\title{
Metabolic evaluation of patients with recurrent idiopathic calcium nephrolithiasis
}

\author{
B. Hess ${ }^{1}$, U. Hasler-Strub ${ }^{1}$, D. Ackermann ${ }^{2}$ and Ph. Jaeger ${ }^{1}$ \\ ${ }^{1}$ Policlinic of Medicine and ${ }^{2}$ Department of Urology, University Hospital, Berne, Switzerland
}

\begin{abstract}
Background. Metabolic evaluation in recurrent idiopathic calcium renal stone-formers (RCSF) was analysed with respect to the following questions: (1) do three 24-h urines provide more diagnostic accuracy in the metabolic evaluation of RCSF than 1 or 2 urines?; (2) does time after stone event influence the diagnostic yield?; (3) is urine composition at weekends different from that at mid-week?; (4) what are the prevalences of the most important risk factors (RF) of idiopathic calcium nephrolithiasis, i.e. low volume (LV), hypercalciuria (HC), hyperoxaluria ( $\mathrm{HO})$, hyperuricosuria (HU), hypocitraturia (Hypo-Cit), and hypomagnesiuria (Hypo-Mg)?; and (5) do male RCSF differ from females with respect to urinary RFs?
\end{abstract}

Methods. Seventy-five RCSF (59 men, 16 women) collected three 24-h urines (U1-3) while on free-choice diet. To account for possible variations in lifestyle and diet, U1 and U3 had to be collected midweek and U2 at a weekend.

Results. When considering all three urines together $(\mathrm{U} 1+\mathrm{U} 2+\mathrm{U} 3)$, the number of RF abnormalities/ patient was $2.8 \pm 0.1$, higher than numbers of any combination of two urines or of any single urine $(P=$ 0.0001 for all comparisons). The number of RF abnormalities also rose with time after stone event, from $0.8 \pm 0.1$ (range $0-4$ ) in U1 to $1.1 \pm 0.1$ (range $0-4$ ) in U3 $(P=0.011$ vs U1). Whereas all other RF did not change between collections, urine volume was lower in $\mathrm{U} 2(1793 \pm 90 \mathrm{ml})$ than in $\mathrm{U} 1(2071 \pm 97 \mathrm{ml}, P=0.0001$ vs U2) and U3 (1946 $\pm 97 \mathrm{ml}, P=0.046$ vs U2). At least 1 abnormality was found in $85.3 \%$ of all RCSF, and multiple abnormalities occurred in $47 \%$. The most frequent RF was $\mathrm{HC}(39 \%)$, followed by $\mathrm{HO}$ and $\mathrm{LV}$ (32\% each), Hypo-Cit (29\%), HU (23\%) and Hypo$\mathrm{Mg}(19 \%)$. Males more often had Hypo-Cit $(P<0.001)$ and Hypo-Mg $(P<0.01)$ than females, whereas HO was more frequent in female $\operatorname{RCSF}(P<0.025$ vs males).

Conclusions. Diagnostic accuracy of metabolic evaluation in RCSF increases both with the number of

Correspondence and offprint requests to: PD Dr Bernhard Hess, Department of Medicine, University Hospital, CH-3010 Berne, Switzerland. urines collected and the time passing after a stone event. Urines collected at weekends differ from those of the week only by their lower volumes. Abnormalities of RF for calcium nephrolithiasis can be detected in $85.3 \%$ of $\mathrm{RCSF}$, and $\mathrm{HC}$ is the most common RF both in male and female RCSF.

Key words: hypercalciuria; hyperoxaluria; hypocitraturia; idiopathic calcium nephrolithiasis; low urine volume; metabolic evaluation

\section{Introduction}

Renal stone formation is a common disorder: up to $15 \%$ of the population will develop kidney stones over a lifetime [1]. About $80 \%$ of all stones that are formed contain calcium, mainly in the form of calcium oxalate [2]. Since renal stone formation is the ultimate consequence of increased urinary supersaturation with calcium salts and most therapeutic approaches focus on reducing supersaturation [3], metabolic evaluation in clinical practice has primarily to consider risk factors of increased urinary supersaturation.

The question whether all patients with nephrolithiasis, in particular those with a first renal colic, should undergo thorough metabolic evaluation, has been addressed by several authors. A meta-analysis of six large retrospective studies [4] concluded that, given the relatively low morbidity associated with a first stone episode and the rather high risk of side-effects with so-called specific therapy, single stone-formers should not undergo elaborate testing of 24-h urines. However, Drach [5] has strongly recommended more elaborate evaluation also in single stone-formers when either a positive family history of stone disease or evidence for additional stones on radiographic evaluation is present, or when specific economic pressure (such as in the case of airline pilots) or the patient's simple desire to know more about the cause of his disease warrant a thorough diagnostic approach. Finally, Tiselius [3] advocates a particularly careful evaluation of all single calcium stone-formers with 
stone episode complicated by either a residual stone or the need of some form of active stone removal.

Another question that arises is whether recurrent calcium stone-formers should undergo metabolic evaluation while on their customary free-choice diet $[2,3,5-7]$, or while on a standardized regimen for several days, possibly under metabolic ward conditions [8]. In the past, Pak and co-workers studied patients while they were collecting two 24-h urines on a free choice diet, before a third urine collection as well as an oral calcium loading test, in order to differentiate between absorptive and renal hypercalciuria, were performed after 7 days on a diet restricted in calcium, sodium, and oxalate [9]. However, due to the fact that absorptive and renal forms of hypercalciuria are probably not distinct entities, but rather two extremes of a continuum behaviour [10], oral calcium loading does not seem to be warranted for routine workup of calcium renal stone-formers.

Since urinary excretion rates of stone-forming compounds strongly depend on dietary habits [6], it has been suggested that tightly controlled metabolic conditions might allow for better distinguishing between 'dietary' and 'metabolic' risk factors of stone formation [8]. However, nutrition is so closely related to the metabolic pathways of oxalate $[11,12]$ as well as of calcium $[11,13,14]$ and citrate $[11,14-16]$, that dietary and metabolic risk factors cannot easily be disentangled. In addition, metabolic ward conditions are far from a patient's individual homeostasis at the time of stone formation. Therefore, any conclusions drawn from such studies might be seriously questioned with respect to clinical relevance.

The present study evaluates recurrent calcium renal stone-formers under original conditions of stone formation, i.e. on their free-choice diet [16], by means of three 24-h urine collections, as recommended by Coe and Parks 'for better surety' [17]. Since it has never been critically studied how many 24-h urines must be collected to obtain an adequate metabolic profile, the main purpose of the present study was to find out whether three urine collections indeed provide more diagnostic accuracy than one or two. Using an ambulatory protocol, we additionally wanted to address the following questions: (1) does time after passage of stones or urological intervention influence the frequency of urine abnormalities that can be detected?; (2) are there differences in 24-h urine compositions between weekdays and weekends?; (3) what are the prevalences of the most important urinary risk factors of recurrent idiopathic calcium nephrolithiasis?; and (4) do male patients differ from females with respect to urinary risk factors of recurrent idiopathic calcium nephrolithiasis?

\section{Subjects and methods}

The following protocol for metabolic evaluation of all recurrent renal stone formers, as summarized in Figure 1, has been established at the Policlinic of Medicine, University of

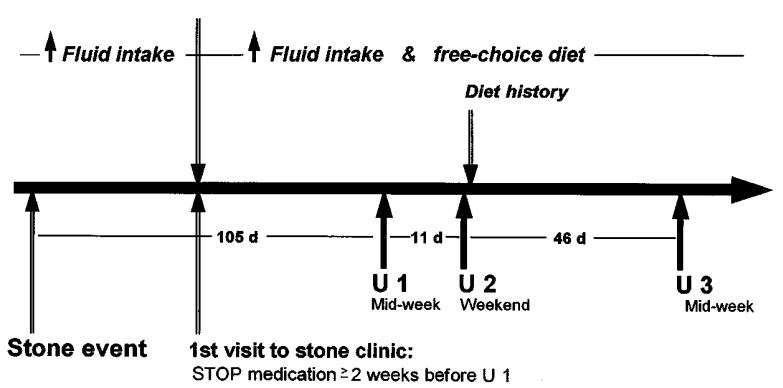

Fig. 1. Protocol for ambulatory evaluation of recurrent renal stoneformers. U1, U2 and U3: 24-h urine collections no. 1, 2 and 3. Stone event: see text for definition.

Berne: after a 'stone event', defined either as urological intervention for acute stone disease (extracorporeal shock wave lithotripsy or endourological treatment) or as spontaneous passage of a stone, patients were advised by their treating physicians to increase fluid intake, before they were referred to the stone clinic for metabolic workup.

During the first visit, when a careful history was taken and a physical examination was performed, patients were asked to keep unchanged the original free-choice diet they used to have when they formed their stones. All medications known to interfere with urinary excretion rates of stone forming substances were discontinued at least 2 weeks prior to metabolic evaluation. Beginning at least 2 months after an event, when they presumably had returned to their original drinking and eating habits, patients first collected two 24-h urines. Since drinking and dietary habits as well as lifestyle at weekends might be different from those during the week, patients were told to collect the first urine (U1) midweek and the second one (U2) during a weekend (from Sunday to Monday). In accordance with our standard protocol [16], sampling of fasting venous blood and 2-h fasting urine was performed at the end of collection period U1, in order to exclude established causes of calcium renal stone formation (see following paragraph). After the weekend collection (U2) had been completed, a preliminary diagnosis was made, and patients were called in by the physician of the stone clinic in order to discuss results and therapeutic options. On this occasion, they provided a third 24-h urine (U3), which they again had collected midweek (Figure 1).

Included in the present analysis are 75 idiopathic calcium renal stone-formers who had exactly followed this protocol, as verified by one of us (UH-S) by means of calendars and dates when laboratory data were obtained. These 75 RCSF met the following criteria: (1) passage or removal of at least two calcium-containing stones, defined either by stone analysis (infrared spectrometry or X-ray diffraction) or disappearance of previously noticed opaque material on conventional radiographs or excretory urograms; (2) no established cause of calcium stone formation, such as primary hyperparathyroidism, hyperthyroidism, sarcoidosis, excessive vitamin $\mathrm{D}$ intake, overt renal tubular acidosis, medullary sponge kidney, hypercalciuria due to hypercalcaemia of malignancy or immobilization, or enteric hyperoxaluria; (3) no clinical evidence of bone disease; (4) normal plasma creatinine concentration $(<116 \mu \mathrm{mol} / 1$ for men and $103 \mu \mathrm{mol} / 1$ for women respectively); (5) absence of urinary tract infection and/or evidence for renal scarring on sonograms; and (6) no stones containing struvite or carbonate apatite.

Twenty-four-hour urines were collected in 3-litre plastic bottles containing $10 \mathrm{~g}$ of boric acid as preservative agent 
$[16,18]$; an internal study in collaboration with the Laboratory of Clinical Chemistry at the University of Berne had revealed that concentration measurements of urinary constituents as well as of $\mathrm{pH}$ did not differ from those obtained in the presence of thymol, a widely used preservative agent [18]. Urine $\mathrm{pH}$ was measured by a Metrohm $654 \mathrm{pH}$ meter (Metrohm, Herisau, Switzerland). All specimens were analysed for creatinine (Crea), calcium (Ca), phosphate $(\mathrm{P})$, sodium $(\mathrm{Na})$, potassium $(\mathrm{K})$, chloride $(\mathrm{Cl})$, magnesium $(\mathrm{Mg})$, uric acid (UA), and urea by autoanalyser techniques. Oxalate (Ox) was measured after enzymatic oxidation by oxalate oxidase, citrate (Cit) using the citrate lyase method, and sulphate (Sulph) by an HPLC system requiring an anion column to separate sulphate from other urinary anions, as previously described [16]. Urinary excretion rates of urea, $\mathrm{P}, \mathrm{UA}$, and Sulph were taken as markers of protein consumption, and $\mathrm{U}_{\mathrm{Na}} \times \mathrm{V}$ as a measure of sodium intake. Net gastrointestinal absorption of alkali (GI-Alkali, expressed in $\mathrm{mEq} / 24 \mathrm{~h}$ ) was derived from $24-\mathrm{h}$ urine excretions of noncombustible cations and anions according to the formula

$(\mathrm{Na}+\mathrm{K}+\mathrm{Ca}+\mathrm{Mg})-(\mathrm{Cl}+1.8 \times \mathrm{P})[19]$

where electrolyte excretions are in $\mathrm{mEq} /$ day except for $\mathrm{P}$ which is in mmol/day with an average valence of 1.8 [19].

Low urine volume (LV), hypercalciuria (HC), hyperoxaluria (HO), hyperuricosuria (HU), hypocitraturia (Hypo-Cit), and hypomagnesiuria (Hypo-Mg) were considered as main urinary risk factors for calcium renal stone formation [1] According to clinical practice, occurrence of a risk factor was defined as presence of an abnormality in at least one of the three 24-h urine samples. Normal values for 24-h urinary excretion rates are based on single 24-h urine collections from 103 male and 73 female healthy volunteers living in the area of Berne, Switzerland, while on a free-choice, regular Swiss diet. Exactly as RCSF, volunteers were individually instructed by a nurse of the Renal Stone Clinic in how to collect a 24-h urine specimen accurately; urines were collected at the same time period as in RCSF. None of the volunteers had ever passed a kidney stone nor was the familiy history positive for renal stone disease. Age of volunteers was $36.2 \pm 1.0$ years (range 22-62) in males and $41.7 \pm 1.6$ years (range 22-63) in females respectively; body-weight was $74.0 \pm 0.9 \mathrm{~kg}$ in males and $59.9 \pm 1.1 \mathrm{~kg}$ in females respectively. Upper normal levels (95th percentile) of excretion rates are $9.00 \mathrm{mmol} / \mathrm{day}$ (men) and $8.00 \mathrm{mmol} /$ day (women) respectively, for $\mathrm{Ca}$; $440 \mu \mathrm{mol} /$ day for Ox (both sexes); $5.00 \mathrm{mmol} /$ day (men) and $4.00 \mathrm{mmol} /$ day (women) respectively, for UA. Lower normal levels (5th percentile) for Cit are $1.70 \mathrm{mmol} /$ day (men) and $1.90 \mathrm{mmol} /$ day (women) respectively; and for $\mathrm{Mg}$ are $3.00 \mathrm{mmol} /$ day (men) and $2.20 \mathrm{mmol} /$ day (women) respectively. Since the risk of calcium stone formation has been demonstrated to increase exponentially with decreasing urine volumes at or below $1200 \mathrm{ml} /$ day [20], 'low volume' was defined as $1200 \mathrm{ml} /$ day or less.

All values are presented as means SE. Non-parametric Mann-Whitney $\mathrm{U}$ test for comparisons between and Wilcoxon signed-rank test for comparisons within groups as well as the $\chi^{2}$ test for comparing frequencies of urine abnormalities were used.

\section{Results}

Among the 75 RCSF that we studied, 59 were male and 16 female. There were no differences between males and females in terms of age $(43.7 \pm 1.5$ and $46.3 \pm 3.1$ years respectively), total number of stones

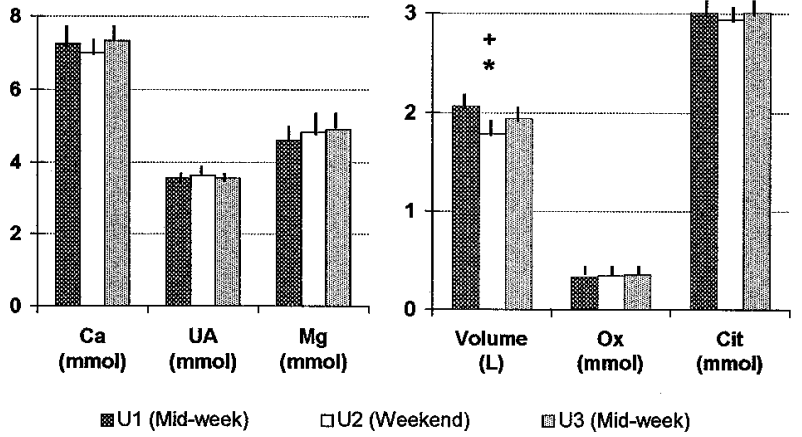

Fig. 2. Mean daily excretions of main urinary risk factors of calcium nephrolithiasis among 75 RCSF (59 men, 16 women). For abbreviations, see text. ${ }^{+} P=0.047$ vs $\mathrm{U} 3 ;{ }^{*} P=0.0001$ vs $\mathrm{U} 1$.

$(9.3 \pm 3.5$ and $4.1 \pm 0.5$ respectively) and stone disease activity (number of stones/years of disease, $0.90 \pm 0.13$ and $0.75 \pm 0.20$ stones/year respectively). The average time lags between the last stone event and urine collections in all 75 RCSF (Figure 1) were $105 \pm 7$ days for $\mathrm{U} 1,116 \pm 7$ days for $\mathrm{U} 2$, and $163 \pm 8$ days for $\mathrm{U} 3$ respectively.

Figure 2 summarizes mean excretion rates of the main parameters relevant to urinary supersaturation of calcium oxalate in all three 24-h urine collections. Except for urinary volume, which was significantly lower in urines collected at weekends, risk factors did not change significantly between the three collection periods in the whole group of RCSF. In female RCSF only, $\mathrm{U}_{\mathrm{Ox}} \times \mathrm{V}$ increased from $347 \pm 53 \mu \mathrm{mol} /$ day in $\mathrm{U} 1$ to $425 \pm 64 \mu \mathrm{mol} /$ day at weekends (U2, $P=0.030 \mathrm{vs}$ $\mathrm{U} 1$ ) and was at $420 \pm 65 \mu \mathrm{mol} /$ day in U3 (NS vs U1 and U2) (Table 1). In all RCSF together, $\mathrm{U}_{\text {Urea }} \times \mathrm{V}$, a urinary marker of protein intake, tended to fall from $409 \pm 14 \mathrm{mmol} /$ day in $\mathrm{U} 1$ to $389 \pm 15 \mathrm{mmol} /$ day at weekends (U2, NS), and increased to $425 \pm 19 \mathrm{mmol} /$ day in $\mathrm{U} 3(P=0.027 \mathrm{vs} \mathrm{U} 2)$. The other urinary markers for protein intake, i.e. $U_{P} \times V$, $\mathrm{U}_{\mathrm{UA}} \times \mathrm{V}$, and $\mathrm{U}_{\text {Sulph }} \times \mathrm{V}$, remained unchanged throughout the three 24-h urine collection periods, as did urinary excretion rates of sodium, potassium, and chloride as well as GI-Alkali; the latter amounted to $45 \pm 3 \mathrm{mEq} /$ day in U1, $40 \pm 3 \mathrm{mEq} /$ day in U2, and $42 \pm 3 \mathrm{mEq} /$ day in $\mathrm{U} 3$ respectively.

Figure 3 depicts the numbers of patients among the $75 \mathrm{RCSF}$ in whom abnormalities of a given urinary risk factor for calcium stone formation were found in at least one of three 24-h urine samples. HC occurred in $38.7 \%$ of all RCSF and was thus the most frequently observed abnormality; 12 RCSF were found to be hypercalciuric on all three occasions, four on two, and 13 on only one occasion. HO and LV were equally frequent $(32.0 \%$ of all RCSF); two patients were hyperoxaluric in all three collections, nine in two, and 13 on one occasion only. LV was present in all three urines in four RCSF, in two urines in five RCSF, and in only one urine in 15 RCSF. Hypo-Cit occurred in $29.3 \%$ of all RCSF, three times in all three, five times in two, and 14 times in only one of the 24-h urines. 
Table 1. Urinary volumes and excretion rates of urinary risk factors as well as of urea and GI-Alkali in male $(n=59)$ and female $(n=16)$ RCSF

\begin{tabular}{|c|c|c|c|c|c|c|}
\hline Measurement & $\begin{array}{l}\text { U } 1 \\
\text { Male RCSF }\end{array}$ & Female RCSF & $\begin{array}{l}\text { U } 2 \\
\text { Male RCSF }\end{array}$ & Female RCSF & $\begin{array}{l}\text { U } 3 \\
\text { Male RCSF }\end{array}$ & Female RCSF \\
\hline Volume (ml) & $2033 \pm 105$ & $2209 \pm 244$ & $1723 \pm 85$ & $2051 \pm 282$ & $1878 \pm 102$ & $2198 \pm 251$ \\
\hline $\mathrm{U}_{\mathrm{Ca}} \times \mathrm{V}(\mathrm{mmol} /$ day $)$ & $7.42 \pm 0.45$ & $6.49 \pm 0.75$ & $7.17 \pm 0.41$ & $6.37 \pm 0.65$ & $7.35 \pm 0.41$ & $7.24 \pm 0.76$ \\
\hline $\mathrm{U}_{\mathrm{Ox}} \times \mathrm{V}(\mu \mathrm{mol} / \mathrm{day})$ & $335 \pm 14$ & $347 \pm 52$ & $327 \pm 13$ & $425 \pm 64^{\circ}$ & $339 \pm 19$ & $420 \pm 65$ \\
\hline $\mathrm{U}_{\mathrm{UA}} \times \mathrm{V}(\mathrm{mmol} / \mathrm{day})$ & $3.71 \pm 0.13$ & $2.94 \pm 0.22 *$ & $3.73 \pm 0.13$ & $3.21 \pm 0.27$ & $3.67 \pm 0.14$ & $3.11 \pm 0.24$ \\
\hline $\mathrm{U}_{\mathrm{Cit}}^{\mathrm{A}} \times \mathrm{V}(\mathrm{mmol} /$ day $)$ & $2.95 \pm 0.15$ & $3.24 \pm 0.24$ & $2.85 \pm 0.16$ & $3.27 \pm 0.26$ & $2.78 \pm 0.17$ & $3.87 \pm 0.30 *$ \\
\hline $\mathrm{U}_{\mathrm{Mg}} \times \mathrm{V}(\mathrm{mmol} / \mathrm{day})$ & $4.85 \pm 0.20$ & $3.63 \pm 0.21 * *$ & $4.94 \pm 0.25$ & $4.37 \pm 0.49$ & $4.94 \pm 0.21$ & $4.70 \pm 0.34$ \\
\hline $\mathrm{U}_{\text {Crea }} \times \mathrm{V}(\mathrm{mmol} /$ day $)$ & $15.73 \pm 0.34$ & $10.33 \pm 0.58 * * *$ & $15.76 \pm 0.41$ & $11.26 \pm 0.60 * * *$ & $15.71 \pm 0.43$ & $11.33 \pm 0.70 * * *$ \\
\hline $\mathrm{U}_{\text {Urea }} \times \mathrm{V}(\mathrm{mmol} /$ day $)$ & $429 \pm 15$ & $331 \pm 27 *$ & $405 \pm 16$ & $328 \pm 30^{+}$ & $448 \pm 23$ & $334 \pm 27^{*}$ \\
\hline GI-Alkali (mEq/day) & $45.4 \pm 2.9$ & $41.5 \pm 6.1$ & $40.0 \pm 2.7$ & $37.9 \pm 8.7$ & $40.2 \pm 3.5$ & $50.6 \pm 5.7$ \\
\hline
\end{tabular}

The three 24-h urine collections U1 (midweek), U2 (weekend) and U3 (midweek) are listed separately. ${ }^{+} P<0.05 ;{ }^{*} P<0.01 ;{ }^{* *} P<0.005$; $* * * P<0.001$ vs male $\mathrm{RCSF} ;{ }^{\circ} P=0.030$ vs $\mathrm{U} 1$ in female RCSF.

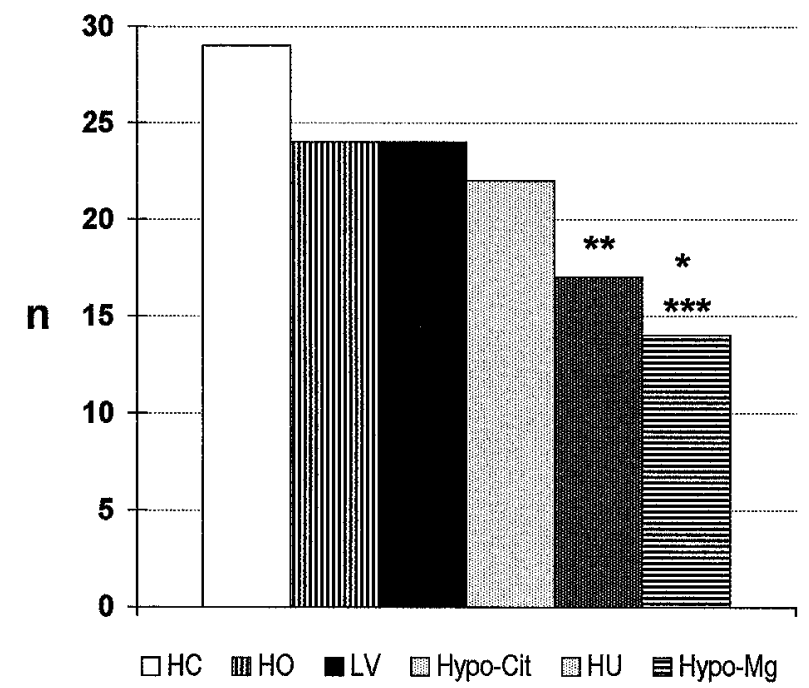

Fig. 3. Numbers of RCSF $(n)$ with an abnormality of a given urinary risk factor in at least one 24 -h urine. For abbreviations, see text $* P<0.025$ vs $\mathrm{HO}$ and $\mathrm{LV}$ respectively; $* * P<0.01$ vs $\mathrm{HC}$; $* * * P<0.0 .001$ vs $\mathrm{HC}$.

HU (22.7\% of RCSF) and Hypo-Mg (18.7\% of RCSF) were clearly the least frequent abnormalities.

Figure 4 shows the mean numbers of risk factor abnormalities/patient detected in single 24-h urine collections as well as in combinations of 2 or 3 urines. When taking all three 24-h urine collections together $(\mathrm{U} 1+\mathrm{U} 2+\mathrm{U} 3), 2.79 \pm 0.26$ abnormalities (range $0-8$ ) per patient were present, and at least one abnormality was found in $85.3 \%$ of the patients, i.e. 64 of 75 RCSF. On the other hand, the early single urine collection U1 revealed only $0.83 \pm 0.10$ abnormalities per patient (range $0-3$ ), and 33 RCSF (44.0\%) did not exhibit any abnormality. Using Wilcoxon signed-rank test, numbers of risk factor abnormalities/patient detected in $\mathrm{U} 1+\mathrm{U} 2+\mathrm{U} 3$ clearly exceeded those found in any combination of two urines or in any single urine $(P=$ 0.0001 for all comparisons). The same was true for any combination of two urine collections in comparison with single urines ( $P=0.0001$ for all comparisons).

Figure 4 also demonstrates that the diagnostic yield of 24-h urine collections increased with time after a

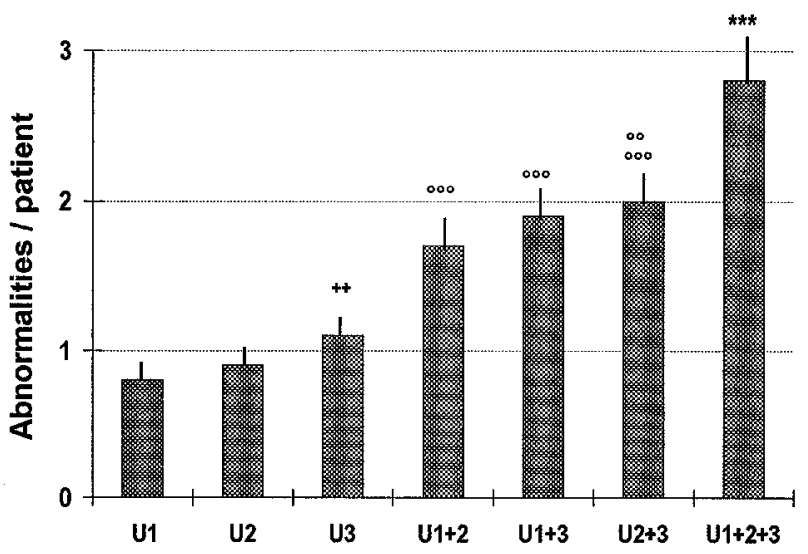

Fig. 4. Number of urinary risk factor abnormalities/patient (mean $\pm \mathrm{SE})$ of RCSF in 24-h urine collections U1 (105 \pm 7 days after stone event), U2 (116 \pm 7 days after event) and U3 (163 \pm 8 days after event) as well as in combinations of two 24-h urines and in all three $24-\mathrm{h}$ urines $(\mathrm{U} 1+2+3) .^{++} P=0.011$ vs $\mathrm{U} 1 ;{ }^{\circ} P=$ $0.011 v s \mathrm{U} 1+2 ;{ }^{\circ 0} P=0.0001 v s$ any single urine; ${ }^{* * *} P=0.0001 v s$ any combination of two urines and $v s$ any single urine.

stone event: compared with U1, mean numbers of risk factor abnormalities/patient were significantly higher in U3 $(1.08 \pm 0.11$ vs $0.83 \pm 0.10, P=0.011)$, as they were in $\mathrm{U} 2+3$ in comparison with $\mathrm{U} 1+2(1.96 \pm 0.18$ vs $1.71 \pm 0.18, P=0.011)$. When all three urine collections were considered together, between two and four risk factor abnormalities were present in 35 of 75 RCSF (46.7\%), whereas 29 RCSF (38.6\%) had only 1 and 11 had no risk factor abnormality present.

When mean values of three 24-h urine collections $\left(\mathrm{Mean}_{\mathrm{U} 1-3}\right)$ for each risk factor were taken as 'gold standard', HC occurred in 17 of 75 RCSF (22.7\%); it tended to occur more often in single urines $(19 / 75$ in $\mathrm{U} 1,18 / 75$ in U2, and 20/75 in U3). In Mean ${ }_{\mathrm{U} 1-3}, \mathrm{HO}$ occurred in 11 of 75 RCSF (14.7\%), and similar frequencies were noted in single urines U1 (10/75) and U2 (9/75); in U3, however, HO was present in 18 of $75 \mathrm{RCSF}$ and thus more frequent than in $\mathrm{Mean}_{\mathrm{U} 1-3}$ $(P<0.05)$, U1 $(\mathrm{P}<0.025)$ and U2 $(P<0.005)$. Low volume occurred in 10 of 75 cases $(13.3 \%)$ in Mean $_{\mathrm{U} 1-3}$ and at similar rates in U1 (11/75), U2 (13/75) and U3 $(13 / 75)$. Hypo-Cit was present in 10 of 75 RCSF 
$\left(13.3 \%\right.$, all males) in $\mathrm{Mean}_{\mathrm{U} 1-3}$; its frequency increased with time after stone event, from $7 / 75$ in U1 to $12 / 75$ in U2 and to $14 / 75$ in U3 $(P<0.010$ vs U1, NS vs Mean $\left._{\mathrm{U} 1-3}\right)$. In $\mathrm{Mean}_{\mathrm{U} 1-3}$, HU was detected in only five of $75 \mathrm{RCSF}(6.7 \%)$; respective frequencies increased to $9 / 75$ in U1 and U2 (NS vs Mean $_{\mathrm{U} 1-3}$ ) and to $10 / 75$ in U3 $\left(P<0.05\right.$ vs $\left.\mathrm{Mean}_{\mathrm{U} 1-3}\right)$. Finally, only five of 75 RCSF $(6.7 \%)$ exhibited Hypo-Mg in $\mathrm{Mean}_{\mathrm{U} 1-3}$, a rate not different from the one observed in single urines, i.e. $7 / 75$ in U1 and U2, and 6/75 in U3.

Figure 5 compares male and female RCSF with respect to the frequencies of abnormal urinary risk factors in at least one of the three 24-h urines. Whereas $\mathrm{LV}, \mathrm{HC}$, and HU were similarly distributed among male and female RCSF, HO was more frequent in female stone-formers $(P<0.025)$, in whom it occurred exactly as frequently as $\mathrm{HC}(43.8 \%)$. On the other hand, male RCSF were more often hypocitraturic $(P<0.001)$ and hypomagnesiuric $(P<0.01)$ than females. Table 1 summarizes excretion rates of urinary parameters relevant to urinary supersaturation of calcium oxalate separately for male and female RCSF.

\section{Discussion}

How many 24-h urine samples are best for metabolic evaluation of 'idiopathic' RCSF? To date, this question has never been critically addressed. Logic might predict that the more urines one analyses, the higher the diagnostic yield. Such an attitude, however, would by no means be cost effective. 'For better surety' but without analysis, Coe and Parks [17] always recommend three urine collections on free-choice diet. In a population of truly 'idiopathic' RCSF, the present study demonstrates that the number of detected abnormalities of six major urinary risk factors for calcium stone disease indeed increases with the number of urine collections up to three. The study, however, does not permit the conclusion that three 24-h urine collections are the 'gold standard', since it was not demonstrated

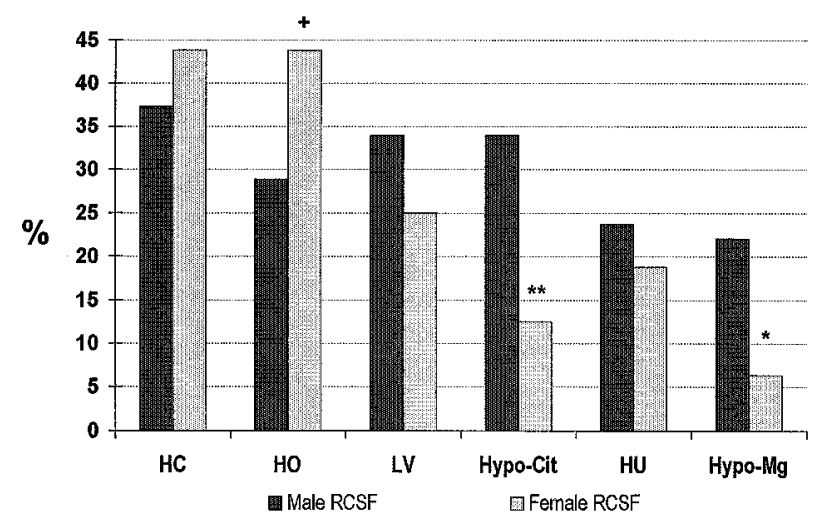

Fig. 5. Frequencies (in \%) of abnormal urinary risk factors of idiopathic calcium nephrolithiasis among male $(n=59)$ and female ( $n=16) \mathrm{RCSF} .{ }^{+} P<0.025$ vs male RCSF; ${ }^{*} P<0.01$ vs male RCSF; $* * P<0.001$ vs male RCSF. For abbreviations, see text. that more than three urine measurements did not provide more diagnostic information.

As demonstrated by Figure 4, the probability of detecting any abnormal risk factors of calcium nephrolithiasis not only increases with the number of urine collections, but also with time after stone event. Significantly more abnormal risk factors were detected in U3, collected 163 days after a stone event, than in $\mathrm{U} 1$, collected 105 days after a stone event, as there were more abnormalities present in a combination of two urines collected late after stone event $(\mathrm{U} 2+3)$ than in the one collected earlier on $(\mathrm{U} 1+2)$. Based on six serial 24-h urine collections during a period of 3 months in 11 stone-formers, a similar trend had been observed by Norman et al. [21], who, for this reason, recommended a 3-month delay after a renal colic before assessing urinary risk factors of calcium stone disease. Our results would suggest that an even more extended time lag may be desirable for improving diagnostic yields.

A second asset of the present study is that drinking and dietary habits of stone-formers (as reflected by 24-h urine excretion rates) during the week are compared with those at weekends. Whereas excretion rates of crystal-forming and crystallization rate-lowering compounds do not vary significantly, urine volume is lower at weekends than midweek (Figure 2). This cannot be explained by a vanishing 'stone clinic effect', since volume increased again in collection U3, performed 46 days later (Figure 1). A so-called weekend effect has recently been demonstrated for healthy controls, but not for stone-formers, in that concentrations of some trace elements and electrolytes in early morning urines were raised on Mondays [22]. The authors speculated that this was possibly due to reduced fluid intake or to greater sweat dissipation at weekends [22], a mechanism which might also explain the lower urine volumes at weekends observed in this study.

Based on three 24-h urine collections, we detected abnormalities of urinary risk factors of 'idiopathic' calcium nephrolithiasis in $85.3 \%$ of RCSF; almost half of the cases had multiple abnormalities, as others have observed in the past $[1,9,23]$. In a previous study of ours [24], abnormal urinary risk factors were present in 158 of $184(86 \%)$ single or recurrent calcium stoneformers. Using an update of their 1980 protocol [9], Levy et al. [1] recently reported that they were able to identify metabolic abnormalities in 925 of 976 patients with recurrent 'idiopathic' calcium stone disease, i.e. in $94.5 \%$. This higher diagnostic yield, however, is probably due to a different definition of hypercalciuria. Indeed, using a rather loose $5.00 \mathrm{mmol} / \mathrm{day}$ $\left(200 \mathrm{mg} /\right.$ day) as the upper limit of normal for $\mathrm{U}_{\mathrm{Ca}} \times \mathrm{V}$, $76.4 \%$ [1] of their 'idiopathic' RCSF exhibited hypercalciuria. Such an impact of the definition of hypercalciuria is further emphasized by the fact that in the present study $88 \%$ of RCSF would have been hypercalciuric if an upper normal level of $5.00 \mathrm{mmol} /$ day had been used for $U_{\mathrm{Ca}} \times \mathrm{V}$. Since the applied threshold values in the present study were considerably higher similar to those more recently described by others 
[6,25-27] idiopathic hypercalciuria was present in only $39 \%$ of RCSF, but was still the most prevalent urinary risk factor.

Low urine volume and hyperoxaluria, highly important risk factors for calcium stone formation in the urinary tract, both occurred in $32 \%$ of RCSF. Using a more stringent low normal limit for urine volume, 1.0 litres/day, Levy et al. [1] encountered low volume in $15.3 \%$ of 1270 patients with recurrent nephrolithiasis of any cause. It is noteworthy that LV is the most prevalent isolated risk factor in the present study, i.e. 9 of $75 \mathrm{RCSF}(12 \%)$ had LV as the sole risk factor. In comparison with data from Levy et al. [1] who found about $8 \%$ hyperoxalurics among 976 'idiopathic' RCSF, the prevalence of $32 \%$ for HO that we observed is rather high and possibly reflects the fact that we may have studied patients with a more active stone disease.

Hyperuricosuria was present in $22.7 \%$ of our RCSF; in the series of Levy et al. [1], however, hyperuricosuric calcium nephrolithiasis occurred in 455 out of 976 RCSF, i.e. in $46.6 \%$. This difference most probably reflects different dietary habits in Texas and Switzerland. Hypocitraturia was present in $29.3 \%$ of our RCSF; this is in accordance with data reported in the literature [reviewed in 15], but somewhat higher than in our previous study in which hypocitraturia had been detected in 15\% of male RCSF [16]. Hypomagnesiuria was detected in $18.7 \%$ of RCSF in the present study, compared with $8.8 \%$ in the study of Levy et al. [1], using a much lower normal level of $2.08 \mathrm{mmol} /$ day. In any case, hypomagnesiuria as a single risk factor was only present in three of $75 \mathrm{RCSF}$.

Finally, male and female RCSF distinguished each other by three urinary parameters relevant to idiopathic calcium nephrolithiasis: hyperoxaluria, hypocitraturia, and hypomagnesiuria. Hyperoxaluria was significantly more frequent among women (44\%) than men $(29 \%, P<0.025)$; in fact, $\mathrm{HO}$ was exactly as frequent as $\mathrm{HC}$ in female RCSF. This is in contradiction with Parks and Coe [28] and cannot actually be explained. We confirm, however, previous findings by others [28-30] that women excrete more citrate than men. Furthermore, hypomagnesiuria also occurs less often among female RCSF, which might be due to the fact that the lower limit of normal in our study was considerably lower in women than in men.

In conclusion, the present study demonstrates that the diagnostic accuracy of metabolic evaluation of recurrent calcium renal stone-formers increases both with the number of urines collected and the time passing after a stone event. With respect to dietary and drinking habits, it appears that urines collected at weekends only differ from those of the week by their lower volumes. Using three 24-h urine collections and less stringent normal values for hypercalciuria and hypomagnesiuria than previously reported $[1,9]$, we were able to detect abnormalities of one or more of the six major urinary risk factors for calcium nephrolithiasis in $85.3 \%$ of 'idiopathic' RCSF, and $46.7 \%$ of patients presented with multiple abnormalities.
Hypercalciuria remains the most prevalent risk factor both in male and female RCSF, whereas hypocitraturia occurs more frequently in males.

Acknowledgements. This study was partly supported by the Swiss National Science Foundation (Grants No.32-33543.92 and 32-43448.95). The authors are grateful to Mrs R. Takkinen and Mrs K. Farina from the Calcium Phosphate Laboratory for their skilful technical assistance.

\section{References}

1. Levy FL, Adams-Huet B, Pak CYC. Ambulatory evaluation of nephrolithiasis: an update of a 1980 protocol. Am J Med 1995; 98: $50-59$

2. Wilson DW. Clinical and laboratory approaches for evaluation of nephrolithiasis. J Urol 1989; 141: 770-774

3. Tiselius HG. Investigation of single and recurrent stone-formers. Miner Electrolyte Metab 1994; 20: 321-327

4. Uribarri J, Oh MS, Carroll HJ. The first kidney stone. Ann Intern Med 1989; 111: 1006-1009

5. Drach GW. Evaluation of the urinary stone former. Semin Urol 1984; 2: 12-19

6. Riess C, Hess B, Binswanger U. Fragliche Aussagekraft der chemischen Analyse eines einzelnen 24h-Urins bei rezidivierender KalziumoxalatNephrolithiasis. Klin Wochenschr 1986; 64: 411-416

7. Coe FL, Parks JH, Asplin JR. The pathogenesis and treatment of kidney stones. N Engl J Med 1991; 327: 1141-1152

8. Hesse A. Labordiagnostik beim Harnsteinleiden und Überwachung der Therapie mit Hilfe der Harnanalyse. Ärztl Lab 1984; 30: 273-278

9. Pak CYC, Britton F, Peterson R et al. Ambulatory evaluation of nephrolithiasis: classification, clinical presentation and diagnostic criteria. Am J Med 1980; 69: 19-30

10. Coe FL, Favus MJ, Crockett T et al. Effects of low-calcium diet on urine calcium excretion, parathyroid function and serum $1,25(\mathrm{OH})_{2} \mathrm{D}_{3}$ levels in patients with idiopathic hypercalciuria and in normal subjects. Am J Med 1982; 72: 25-32

11. Goldfarb S. Dietary factors in the pathogenesis and prophylaxis of calcium nephrolithiasis. Kidney Int 1988; 34: 544-555

12. Sutton RAL, Walker VR. Enteric and mild hyperoxaluria. Miner Electrolyte Metab 1994; 20: 352-360

13. Hess B, Ackermann D, Essig M, Takkinen R, Jaeger Ph. Renal mass and serum calcitriol in male idiopathic calcium renal stoneformers: role of protein intake. J Clin Endocrinol Metab 1995; 80: 1916-1921

14. Kok DJ, Iestra J, Doorenbos CJ, Papapoulos SE. The effects of dietary excesses in animal protein and in sodium on the composition and the crystallization kinetics of calcium oxalate monohydrate in urines of healthy men. J Clin Endocrinol Metab 1990; 71: $861-867$

15. Pak CYC. Citrate and renal calculi: new insights and future directions. Am J Kidney Dis 1991; 17: 420-425

16. Hess B, Michel R, Takkinen R, Ackermann D, Jaeger Ph. Risk factors for low urinary citrate in calcium nephrolithiasis: low vegetable fibre intake and low urine volume to be added to the list. Nephrol Dial Transplant 1994; 9: 642-649

17. Coe FL, Parks JH. Nephrolithiasis. In: Favus MJ et al. (eds), Primer on the Metabolic Bone Diseases and Disorders of Mineral Metabolism, 2nd edn. Raven Press, New York, 1993; 399-403

18. Hess B. Nierensteine. In: Colombo JP (ed.), Klinisch-chemische Urindiagnostik. Labolife Verlagsgemeinschaft, Rotkreuz (Switzerland), 1994; 283-294

19. Oh MS: A new method for estimating GI absorption of alkali. Kidney Int 1989; 36: 915-917

20. Robertson WG, Peacock M, Heyburn PJ, Hanes FA. Epidemiological risk factors in calcium stone disease. Scand J Urol Nephrol 1980; [Suppl 53]: 15-28

21. Norman RW, Bath SS, Robertson WG, Peacock M. When should patients with symptomatic urinary stone disease be evaluated metabolically? J Urol 1984; 132: 1137-1139 
22. Rodgers A, Barbour L, Pougnet B, Lombard C, Ryall R. Urinary element concentrations in kidney stone-formers and normal controls: the weekend effect. J Trace Elem Electrolytes Hlth Dis 1994; 8: 87-91

23. Strauss AL, Coe FL, Parks JH. Formation of a single calcium stone of renal origin: clinical and laboratory characteristics of patients. Arch Intern Med 1982: 142: 504-507

24. Jaeger Ph, Portmann L, Jacquet AF, Burckhardt P. Indications au dosage du citrate urinaire dans le bilan d'une lithiase rénale idiopathique. Schweiz Med Wochenschr 1986; 116: 371-373

25. Elliot JS. Calcium oxalate urinary calculi: clinical and chemical aspects. Medicine 1983; 62: 36-43

26. Netelenbos JC, Jongen MJM, van der Vijgh WJF, Lips P, van
Ginkel FC. Vitamin D status in urinary calcium stone formation. Arch Intern Med 1985; 145: 681-684

27. Tschöpe W, Ritz E. Diagnostik der Nephrolithiasis. Dtsch Med Wochenschr 1985; 110: 381-384

28. Parks JH, Coe FL. A urinary calcium-citrate index for the evaluation of nephrolithiasis. Kidney Int 1986; 30: 85-90

29. Nikkila M, Koivula T, Jokela H. Urinary citrate excretion in patients with urolithiasis and normal subjects. Eur Urol 1989; 16: $382-385$

30. Minisola S, Rossi W, Pacitti MT et al. Studies on citrate metabolism in normal subjects and kidney stone patients. Miner Electrolyte Metab 1989; 15: 303-308 